\title{
Utilização de implante ósseo cortical alógeno conservado em glicerina para preservação de membro torácico. Estudo experimental em cães ${ }^{1}$
}

\author{
Liane Ziliotto ${ }^{2}$ \\ Alexandra Pinheiro Fantinatti ${ }^{2}$ \\ Carlos Roberto Daleck ${ }^{3}$ \\ João Guilherme Padilha Filho ${ }^{4}$ \\ Almir Pereira de Souza ${ }^{5}$ \\ Pedro Paulo Vissotto de Paiva Diniz ${ }^{6}$
}

\begin{abstract}
Ziliotto L, Fantinatti AP, Daleck CR, Padilha Filho JG, Souza AP, Diniz PPVP. Utilização de implante ósseo cortical alógeno conservado em glicerina para preservação de membro torácico: estudo experimental em cães. Acta Cir Bras [serial online] 2003 Mar-Abr;18(2). Disponível em URL: http:/ /www.scielo.br/acb.
\end{abstract}

RESUMO - A técnica de preservação de membro é uma alternativa à amputação em cães com osteossarcoma do esqueleto apendicular. Objetivo: O desenvolvimento da técnica preservadora aos moldes da original descrita por Straw ${ }^{1}$. Métodos: $O$ procedimento cirúrgico foi realizado com modificações, substituindo-se o método de conservação dos implantes pela glicerina e o cimento ósseo utilizado no preenchimento do canal medular do implante pela poliuretana de mamona, e para avaliação da incorporação do implante foram feitos exames clínico, radiográfico e histopatológico em diferentes tempos pós-operatórios. Resultados: Observada a boa função do membro no pósoperatório, a formação de calo ósseo e fechamento das linhas de interfaces com remodelação óssea em avaliação radiográfica e ao exame histopatológico foi notada a reabsorção do implante ósseo com sua substituição por tecido conjuntivo fibroso e tecido ósseo compacto, neovascularização e presença de infiltrado inflamatório plasmocitário. Conclusões: A poliuretana de mamona mostrouse uma boa substituta ao cimento originalmente utilizado, aumentando a resistência do implante, sem causar reações do tipo corpo estranho e sem sua osteointegração. O implante ósseo conservado em glicerina apresentou ação osteoindutora e osteocondutora, sem sinais de rejeição; desta forma, a glicerina mostrou ser uma meio alternativo viável. Portanto, a técnica de preservação do membro, com suas modificações, caracterizou-se como alternativa à técnica original e à amputação do membro para cães com osteossarcoma de esqueleto apendicular.

DESCRITORES - Osteossacoma. Glicerina. Poliuretana de mamona. Preservação de membro. Implante ósseo.

1. Dissertação de Mestrado defendida no programa de Pós-graduação em Cirurgia Veterinária da Faculdade de Ciências Agrárias e Veterinárias - Universidade Estadual Paulista, Campus de Jaboticabal.

2. Mestre em Cirurgia Veterinária pela FCAV-UNESP, Campus de Jaboticabal.

3. Professor adjunto-Livre-Docente do Departamento de Clínica e Cirurgia Veterinária, FCAV-UNESP.

4. Professor assistente-Doutor do Departamento de Clínica e Cirurgia Veterinária, FCAV-UNESP.

5. Mestre em Medicina Veterinária pela Universidade Federal de Viçosa.

6. Médico Veterinário pela FCAV-UNESP. 


\section{Introdução}

Os animais com osteossarcoma do esqueleto apendicular têm sido tratados na atualidade, em nosso país, apenas com amputação do membro e terapia adjuvante, seja com quimioterapia seja com imunoterapia. Um grande número de proprietários se recusa a autorizar a amputação do membro afetado, impossibilitando, dessa maneira, que o profissional realize uma terapia mais adequada, o que, conseqüentemente, reduz as chances de proporcionar ao animal maior sobrevida com melhor qualidade de vida.

A técnica de preservação de membro foi desenvolvida para os casos especiais, em que o proprietário não permite a amputação do membro, ou para animais que, além da neoplasia óssea, apresentam alterações neurológicas ou outras afeções ortopédicas que impossibilitem a realização da amputação ${ }^{2}$. Em estudos sobre sua viabilidade prática, foi concluído que ela promove a função de boa a excelente do membro, na maioria dos casos, não havendo diferenças na sobrevida dos animais quando comparada à amputação ${ }^{3}$.

Originariamente, a técnica conservadora consiste na remoção da área afetada pelo tumor, com boa margem de segurança, seguindo-se a fixação de um implante ósseo alógeno congelado ao rádio, metacarpo e terceiro metacarpiano, com auxílio de uma placa de autocompressão e parafusos na qual o canal medular do implante é preenchido com cimento ósseo estéril (polimetil metacrilato) ${ }^{1}$.

O uso dos implantes ósseos vem se expandindo e na busca de novos métodos de conservação de tecidos a glicerina pura foi adotada na conservação de fragmentos ósseos por Costa ${ }^{4}$. A glicerina mostrou preservar as funções osteocondutoras e osteoindutoras destes implantes e atuou como um bom meio conservador por ter poder de redução da antigenicidade, baixo custo, preparo simples e facilidade de estocagem e utilização ${ }^{5,6}$. Porém, foi observada uma redução na resistência dos fragmentos ósseos, semelhante ao que ocorre quando outros métodos de conservação são utilizados ${ }^{4}$. Com o intuito de se aumentar a resistência dos implantes, especialmente na técnica de preservação do membro, foi adotado o uso de polímeros em seu canal medular ${ }^{7 e 8}$. Em 1984, Chierici desenvolveu a resina poliuretana extraída do óleo da mamona, que se mostrou compatível com as propriedades de um biopolímero ${ }^{9,10}$. Esta poliuretana foi utilizada em cães por Ignácio em $1999^{11}$ e posteriormente por Maria em 2001'12, e mostrou ser biocompatível e biotolerante, sem que ocorresse sua osteointegração.
Com o objetivo de se tornar a técnica preservadora factível em nosso país, foi utilizada a glicerina como meio conservador de implantes ósseos alógenos com seus canais medulares preenchidos com a poliuretana de mamona e fixados por placa de autocompressão para a correção de falha óssea promovida em rádio distal, semelhante à técnica descrita por $\mathrm{Straw}^{1}$, observando-se, assim, o comportamento da poliuretana como cimento ósseo e do implante ósseo conservado em glicerina como substituto do congelado.

\section{Métodos}

\section{Animais}

Foram utilizados seis cães sadios, adultos, sem raça definida, pesando entre 20 a $32 \mathrm{~kg}$, sendo quatro machos e duas fêmeas, obtidos junto ao Canil Central do Hospital Veterinário "Governador Laudo Natel" da FCAV-UNESP, Campus de Jaboticabal e aclimatados em canis individuais recebendo ração balanceada e água ad libitum.

\section{Grupos experimentais}

Os animais foram divididos em três grupos com dois animais cada, submetidos ao procedimento cirúrgico e eutanasiados nos seguintes tempos pósoperatórios:

Grupo 1: aos 90 dias

Grupo 2: aos 120 dias

Grupo 3: aos 150 dias

\section{Implantes ósseos}

Foram coletados as epífises de rádio de animais eutanasiados por indicações não infecciosas ou neoplásicas. Os fragmentos ósseos foram lavados e colocados em frasco com glicerina a $98 \%$ por no mínimo 30 dias. Decorrido este tempo, os mesmos tiveram seu canal medular preenchido com a poliuretana de mamona e retornaram ao frasco com glicerina, onde permaneceram até o momento da cirurgia.

\section{Pré-operatório e anestesia}

Foi realizada a antibioticoprofilaxia com cefalexina monohidratada, por via oral, na dose de $30 \mathrm{mg} / \mathrm{kg}$ de peso vivo, a cada 12 horas, com início 24 horas antes do procedimento cirúrgico. Os animais foram submetidos a jejum alimentar de 12 horas e restrição hídrica de 6 horas e foram feitos exames radiográficos do membro anterior direito em visão dorso-ventral e médio-lateral. 
Para o procedimento anestésico foi utilizada a acepromazina na dose de $0,1 \mathrm{mg} / \mathrm{kg}$ de peso e tiopental sódico na dose de $12,5 \mathrm{mg} / \mathrm{kg}$ de peso, ambos por via intravenosa, para a indução anestésica. A manutenção foi feita pela via inalatória, com o halotano, em circuito fechado.

\section{Procedimento cirúrgico}

Os animais foram posicionados em decúbito dorsal, com o membro torácico direito elevado, seguindo-se a tricotomia, anti-sepsia com álcool e iodo polivinil pirrolidona, e sua extremidade protegida com malha tubular estéril. A manobra operatória foi realizada com a incisão dorso-lateral no antebraço, iniciando-se proximalmente à articulação úmero-rádio-ulnar até a articulação metacarpo falangeana (Figura 1A). Após dissecção dos tecidos moles adjacentes e secção do músculo abdutor longo do primeiro dedo, a cápsula da articulação do carpo foi incisionada com bisturi, perto da linha proximal dos ossos do carpo (Figura 1B). Um fragmento ósseo de aproximadamente um terço do comprimento total do rádio foi removido utilizando-se serra manual, sendo a ulna seccionada sagitalmente e o córtex medial da ulna removido juntamente com o fragmento ósseo de rádio (Figura $1 \mathrm{C}$ ). A secção da margem distal foi feita na articulação rádio-carpal, com
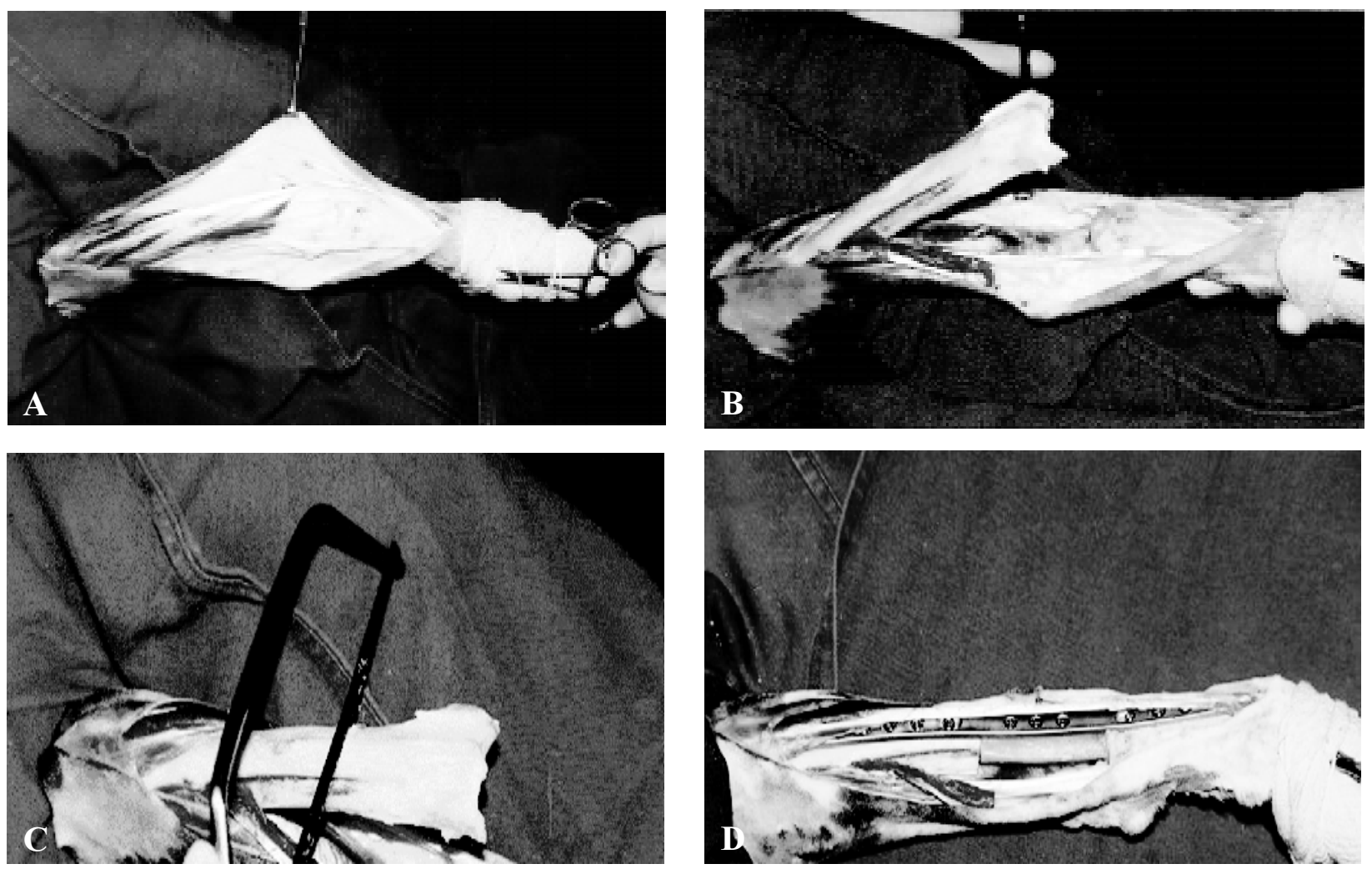

FIGURA 1 - Seqüência fotográfica do procedimento cirúrgico, mostrando em A) o acesso cirúrgico com a incisão dorso-lateral no antebraço e dissecção dos tecidos moles adjacentes, B) a incisão da cápsula da articulação rádio-carpal e divulsão de tecidos moles adjacentes ao rádio e a ulna, C) a ostectomia de fragmento do rádio e da ulna com auxílio de serra manual, após ter sido realizada a secção da cartilagem da articulação proximal do carpo (cartilagem dos ossos intermedioradial e ulnar), também com auxílio de serra manual, D) aspecto final do procedimento cirúrgico onde observa-se a placa metálica fixada ao rádio, articulação do carpo e terceiro metacarpiano. Notar que foi realizada a artrodese da articulação do carpo. 


\section{Pós-operatório}

A automutilação foi evitada com o uso de colar elisabetano, sendo removido no momento da retirada dos pontos. Foram feitos curativos diariamente por 10 dias. Mantida a cefalexina monohidratada, na dose de $30 \mathrm{mg} / \mathrm{kg}$ de peso corporal, por via oral, a cada 12 horas, por sete dias.

O ketoprofeno foi fornecido como analgésico na dose de $2 \mathrm{mg} / \mathrm{kg}$ de peso, por via subcutânea, no pósoperatório imediato e a cada 24 horas, por quatro dias.

Exercícios foram restringidos, mas o uso do membro foi encorajado, com exercícios leves diários desde o primeiro dia do pós-operatório.

\section{Avaliação clínica}

Os animais foram examinados diariamente, avaliando-se o estado geral, a temperatura corporal, os aspectos clínicos da ferida cirúrgica e do membro operado, a presença de claudicação, anotando-se o momento de apoio e o momento em que o membro foi utilizado normalmente.

A claudicação foi avaliada e quantificada em graus (Sumner-Smith, 1988), onde: grau 0: sadio; grau 1: ocasionalmente desvia o membro; grau 2: leve claudicação durante o trote lento; nenhuma durante a marcha; grau 3: leve claudicação durante a marcha; grau 4: claudicação evidente durante a marcha; mas apóia o membro quando em estação; grau 5: graus de gravidade do grau 4; grau 6: graus de gravidade do grau 4; grau 7: graus de gravidade do grau 4; grau 8: graus de gravidade do grau 4; grau 9: apóia o dedo quando em estação, sustenta o membro durante o trote; grau 10: incapaz de apoiar o membro no solo.

\section{Avaliação radiográfica}

Os animais foram avaliados radiograficamente nos períodos pré-operatório, pós-operatório imediato e com $7,15,30,45,60,90,120$ e 150 dias de pós-operatório, de acordo com os grupos preestabelecidos, objetivandose analisar a incorporação do implante ósseo ao membro e a regeneração óssea local, nos diferentes tempos.

\section{Eutanásia dos animais}

Os cães foram eutanasiados com injeção rápida de tiopental sódico por via intravenosa associado ao cloreto de potássio até parada completa dos batimentos cardíacos. Após o sacrifício, os animais foram encaminhados para avaliação macroscópica e coleta dos fragmentos para exame histopatológico.
Avaliação macroscópica do membro operado

No momento da necropsia dos animais, antes da coleta do fragmento ósseo para a análise histopatológica, foram observados a reação dos tecidos moles, a formação de calo ósseo e o aspecto do implante ósseo e da placa metálica.

\section{Avaliação histopatológica}

Posteriormente à avaliação macroscópica do membro operado, seguiu-se o corte das duas áreas de contato dos ossos do membro ao implante. Essa secção foi de aproximadamente $2 \mathrm{~cm}$ de comprimento, os fragmentos foram identificados em interface proximal e interface distal, fixados em solução tamponada de formol a $10 \%$, os cortes corados com hematoxilina e eosina e observados em microscópio óptico. $\mathrm{Na}$ avaliação histopatológica objetivou-se avaliar a união óssea nas interfaces, a reabsorção e a revascularização do implante e a remodelação óssea, bem como comparar os aspectos microscópicos com os achados radiográficos.

\section{Resultados}

\section{Procedimento cirúrgico}

O tempo operatório despendido foi, em média, de três horas e cinqüenta minutos, sendo que a moldagem do implante ao membro e o posicionamento da placa foram os passos mais demorados.

\section{Avaliação clínica pós-operatória}

Todos os animais apresentaram hipertermia nos primeiros dias de pós-operatório, voltando a apresentar temperatura normal após uma semana.

Todos os animais apresentaram edema do membro operado por um tempo médio de cinco dias e apresentando redução progressiva.

$\mathrm{Na}$ avaliação subjetiva da dor, todos os animais apresentaram sensibilidade dolorosa acentuada no primeiro dia de pós-operatório à manipulação do membro

Não ocorreram deiscências das suturas e contaminação da ferida.

Todos os animais apresentaram claudicação de grau nas primeiras 24 horas de pós-operatório, e a maioria apresentou claudicação de grau 4 nos primeiros sete dias de pós-operatório, de grau 3 até os 30 dias e de grau 1 a 2 após este período.

Com exceção de um animal, os demais apoiaram o membro operado no primeiro dia de pós-operatório. 
Tal atitude deu-se, inicialmente, sem o apoio do peso corporal, o que aconteceu progressivamente a partir do segundo dia.

O membro foi utilizado ao caminhar a partir do segundo dia de pós-operatório, e ao trote, em média, a partir do $40^{\circ}$ dia.

\section{Avaliação radiográfica pós-operatória}

Imediato: Boa fixação do fragmento ósseo implantado aos ossos receptores (rádio e carpo) em todos animais (Figura 2A).

7 dias: Nenhuma alteração foi notada quando em comparação às imagens do pós-operatório imediato.

15 dias: Notou-se reabsorção discreta da linha das interfaces ósseas e reabsorção de região distal da ulna.
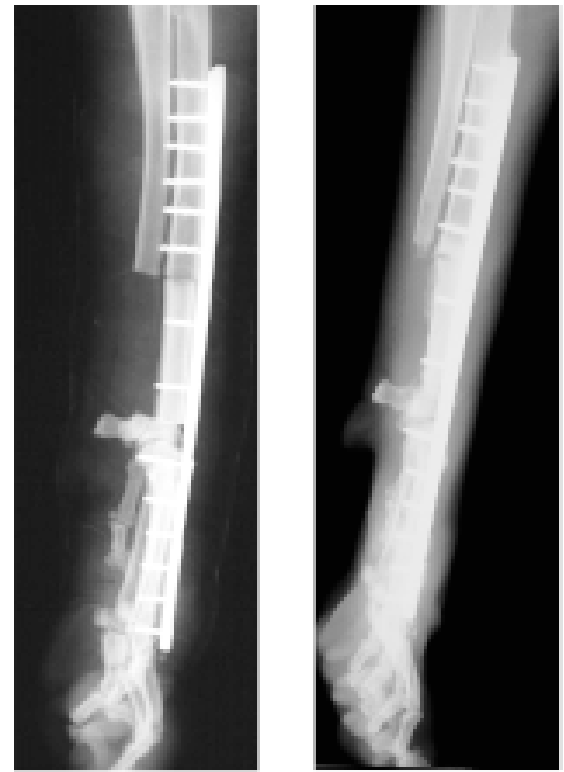

FIGURA 2 - Imagens radiográficas de membro torácico direito de cão, em visão médio-lateral, ilustrando: A) aspecto do pós-operatório imediato; B) aos 90 dias de pós-operatório, observando-se formação de calo ósseo em interfaces, com o fechamento das linhas das interfaces; C) aos120 dias de pós-operatório, mostrando-se o início da remodelação óssea; D) aos 150 dias de pós-operatório, observa-se a remodelação óssea.

\section{Avaliação macroscópica do membro operado}

Observada a presença de tecido fibroso e ósseo recobrindo toda a placa metálica, formação de calo ósseo na região de interfaces, remodelação óssea em região do implante e não-absorção do polímero poliuretano de mamona em todos os grupos.

\section{Avaliação histopatológica}

Interface proximal: presença de resquícios do implante ósseo com sua substituição por tecido conjuntivo fibroso, infiltrado inflamatório difuso entre as fibras
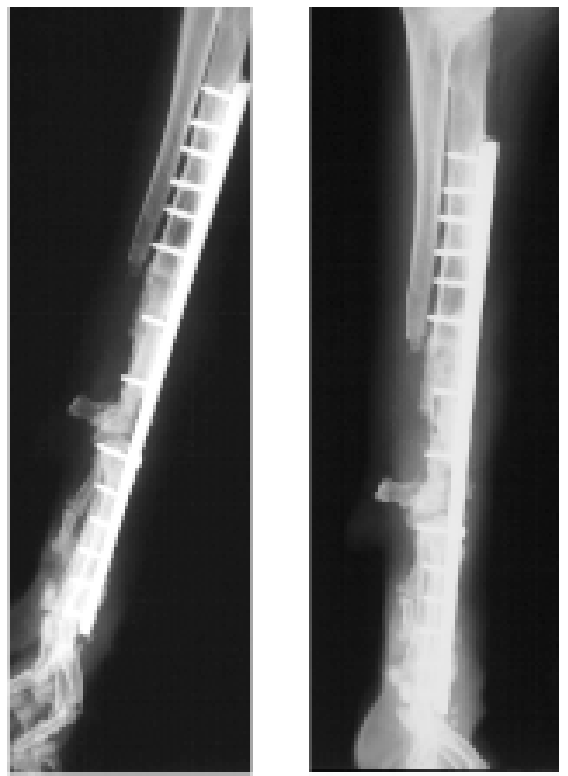

30 dias: Início de reabsorção do implante, início de formação de pontes ósseas em interfaces, entre o rádio e a ulna e entre o implante e o osso acessório do carpo, e o desvio lateral do membro.

45 dias: Reabsorção do implante e formação de pontes ósseas nas interfaces mais acentuadas.

60 dias: Pontes ósseas em interfaces mais evidentes, formação de calo ósseo com fechamento da linha das interfaces ósseas

90 dias: Reabsorção do implante mais evidente, redução da linha das interfaces ósseas, formação de calo ósseo com fechamento das linhas de interface, remodelação óssea (Figura 2B).

120 dias: Quase completa reabsorção do implante, formação de calo ósseo com fechamento de linhas de interfaces ósseas, remodelação óssea (Figura 2C).

150 dias: Remodelação óssea (Figura 2D).

do tecido conjuntivo com predominância de plasmócitos, formação de neovasos e de tecido ósseo compacto (Figura 3A).

Interface distal: formação de tecido conjuntivo fibroso com infiltrado inflamatório notando-se a predominância de plasmócitos; presença de tecido ósseo compacto neoformado, neovasos e medula óssea ativa (Figura 3B).

Foi notada a redução no infiltrado inflamatório nos grupos de 120 e 150 dias e a substituição progressiva de tecido conjuntivo fibroso por tecido ósseo compacto. 

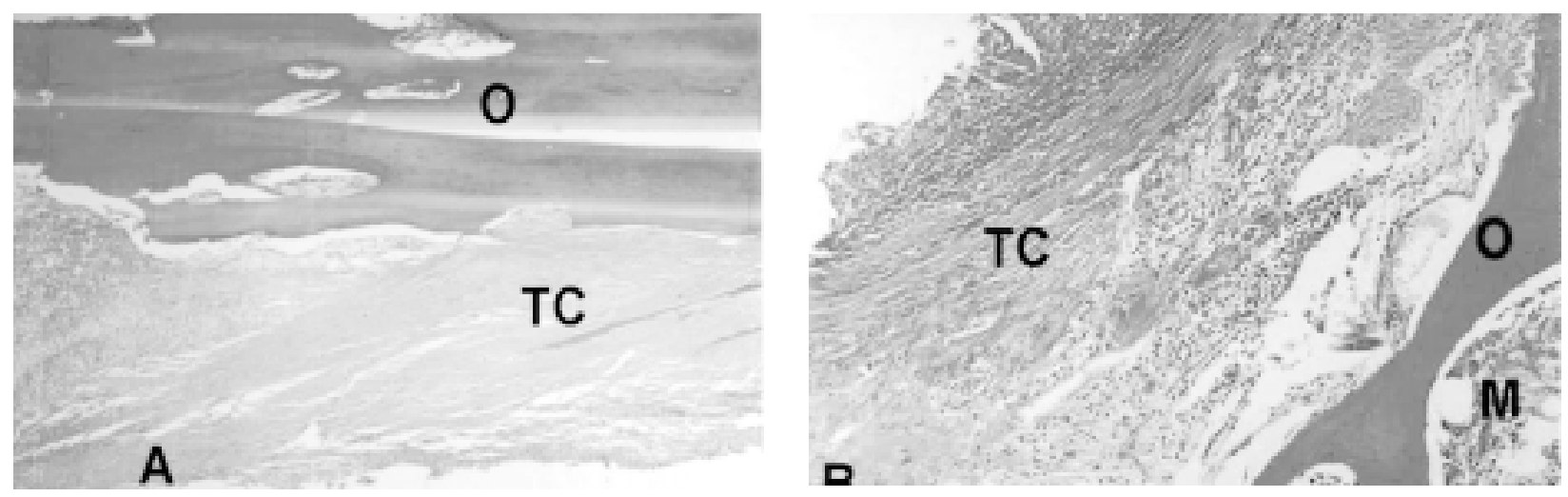

FIGURA 3 - Fotomicrografia com os aspectos dos exames histopatológicos dos cães operados aos 150 dias de pós-operatório, mostrando: A) corte histológico de interface proximal em objetiva 4, onde observa-se a presença de tecido conjuntivo fibroso (TC) e tecido ósseo compacto neoformado (O); B) corte histológico de interface distal em objetiva 10, onde nota-se a presença de tecido conjuntivo fibroso (TC), tecido ósseo compacto neoformado $(\mathrm{O})$ e medula óssea ativa $(\mathrm{M})$.

\section{Discussão}

A técnica preservadora para o tratamento de cães com osteossarcoma de esqueleto apendicular, apesar de freqüentemente utilizada em outros países desde a década de 1980, não tem sido empregada em nosso país. Poucos centros veterinários estão capacitados para sua realização, pois é indispensável que haja atuação multidisciplinar, com profissionais da área de oncologia, ortopedia, radiologia e patologia, além de haver necessidade de um banco de ossos constantemente disponível ${ }^{13}$. No presente estudo foi desenvolvida uma alternativa à técnica original, substituindo-se o método de conservação do implante ósseo cortical alógeno, pela glicerina a $98 \%$ e também o cimento ósseo de pela poliuretana de mamona, visando tornar o procedimento cirúrgico factível em nosso meio.

O implante ósseo cortical alógeno conservado em glicerina a $98 \%$ foi utilizado em cães por Pinto $\mathrm{Jr}^{14} \mathrm{e}$, posteriormente, por $\operatorname{Costa}^{4}$ que observaram diminuição da antigenicidade dos fragmentos ósseos pela redução de sua celularidade. Nos animais submetidos à técnica de preservação de membro não foram notados sinais clínicos, radiográficos ou histopatológicos de rejeição dos implantes, tendo então a glicerina atuado de forma semelhante, como redutora da sua antigenicidade. Não se fizeram necessários cuidados assépticos para a colheita dos fragmentos ósseos, já que as soluções concentradas de glicerina atuam como bactericida e como anti-séptico ${ }^{15}$ e $^{16}$. De fato, não foram encontradas durante o exame clínico e histopatológico evidências de contaminação bacteriana ou fúngica. $\mathrm{O}$ custo de manutenção do banco de ossos com o uso da glicerina foi bem reduzido, sendo o mesmo observado por Leite e col. ${ }^{5}$, Costa $^{4}$ e Costa Neto ${ }^{6}$. Pelo exposto, a glicerina mostrou-se um meio de conservação viável para fragmentos ósseos e bom substituto ao método de congelação originalmente utilizado na técnica de preservação de membro descrita por Straw ${ }^{1}$.

Segundo $\mathrm{Costa}^{4}$, os implantes ósseos conservados em glicerina tornam-se menos resistentes que os fragmentos ósseos frescos, podendo sofrer fraturas no momento da colocação dos parafusos. Porém, esta queda na resistência também ocorre quando a conservação é feita por congelação. Para aumentar a resistência dos implantes ósseos, especificamente na técnica preservadora do membro, o canal medular dos fragmentos ósseos a serem implantados foi preenchido com cimento ósseo ${ }^{7,8}$. O cimento adotado na técnica original é o polimetil metacrilato acrescido de antibiótico no momento do seu preparo ${ }^{8}$. O metil metacrilato é um polímero que apresenta desvantagens por liberar gases tóxicos, desprender calor por reação exotérmica, atingindo temperaturas superiores a $70^{\circ} \mathrm{C}$, e ainda pode provocar fenômenos tromboembólicos e arritmias cardíacas $^{11}$. Em substituição a este polímero foi utilizada a poliuretana de mamona que se mostrou compatível com tecidos vivos, apresentando aspectos favoráveis de processabilidade, flexibilidade de formulação, controle de pico exotérmico na transição líquido-sólido, excelentes propriedades estruturais, ausência de emissão de vapores tóxicos, bom poder de adesão a metais, não liberando radicais tóxicos quando implantada, baixo custo, além de potencial bactericida ${ }^{10,12}$. Segundo Maria $^{12}$, quando empregada na crista tibial, a poliuretana de mamona não desencadeou processos infecciosos ou de rejeição no tecido hospedeiro, sendo biocompatível e permanecendo biotolerante ao longo do tempo, sem osteointegração. Como cimento ósseo, preenchendo o canal medular dos implantes, a poliuretana de mamona proporcionou suporte ao implante durante sua revascularização e incorporação, prevenindo a perda 
de parafusos e a fratura do implante sem sinais de rejeição, portanto sendo biotolerante. Pelo fato de o poliol ter ação bactericida comprovada em ensaio bacteriológico $^{11}$, não foi acrescido qualquer tipo de antibiótico ao polímero de mamona, não sendo observados sinais de contaminação em avaliação clínica e histopatológica, ratificando sua atuação bactericida.

Assim, ao contrário do descrito pela literatura, não foram observados quaisquer sinais de infecção em nenhum dos animais. De acordo com a literatura consultada, a principal complicação da cirurgia de preservação de membro é a infecção com taxas de $31 \%$ a $40 \%$ dos animais operados ${ }^{3,7,13,17-20}$. Tal ausência de infecção se deve ao bom estado geral e nutricional dos animais e principalmente por não se ter utilizado drogas imunossupressoras no pós-operatório, o que normalmente ocorre em animais com osteossarcoma operados pela técnica conservadora ${ }^{7,18}$.

Segundo LaRue e col. ${ }^{3}$, Straw e col. ${ }^{19}$ e Straw e Withrow $^{8}$, que realizaram a técnica preservadora em animais doentes, foi notado o apoio do membro em média aos dez dias de pós-operatório, sendo sua função de boa a excelente na maioria dos casos. Neste trabalho, o apoio do membro e sua utilização durante a marcha foram notados mais precocemente já no segundo dia de pós-operatório. Ao caminhar, a maioria dos animais apresentou claudicação de grau 1 a 2 após os trinta dias de pós-operatório, correspondendo à função do membro de boa a excelente, semelhante ao observado pelos autores supracitados.

A cicatrização em regiões submetidas à implantação óssea é classificada como secundária ou indireta, havendo a substituição do implante por tecido ósseo do animal receptor. Nos cães deste estudo notou-se, aos 15 dias, reabsorção das linhas de interface óssea, portanto com o início da ação dos osteoclastos e neovascularização. A partir dos 30 dias iniciou-se a reabsorção dos implantes ósseos e a formação de pontes ósseas, sendo que, aos 60 dias, foi notada a presença de calo ósseo em um dos animais e, aos 90 dias, nos demais. A remodelação óssea iniciou-se aos 90 dias em um animal e aos 120 dias nos demais. Com base nos conhecimentos citados anteriormente, nota-se que, nos animais experimentais, a consolidação óssea ocorreu de forma apropriada, dentro do descrito pela literatura.

Após avaliação radiográfica, os animais foram eutanasiados de acordo com seus grupos experimentais, e os membros operados avaliados macroscopicamente. Ao exame notou-se a presença de cápsula fibrosa ao redor da placa metálica, que, segundo Sinibaldi ${ }^{21}$, é uma reação do tipo corpo estranho que ocorre com a maioria dos implantes metálicos, variando com o tipo de material utilizado e seus produtos corrosivos. As reações de rejeição aos implantes ósseos são caracterizadas pela reabsorção da periferia do implante sem a substituição por tecido reparador, pelo aumento de fraturas com concomitante redução do diâmetro do implante, pela redução da reparação do implante, pela resposta inflamatória com predominância de linfócitos, pelo tecido fibroso encapsulando o implante, pela oclusão de neovasos com necrose progressiva e ainda pela dor, edema e vermelhidão ${ }^{21-23}$. Apesar de ter sido encontrada cápsula fibrosa ao redor da placa metálica, não foram notados quaisquer sinais clínicos, radiográficos, macroscópicos ou histopatológicos de rejeição aos implantes ósseos, havendo formação de calo ósseo ao redor da junção implante-hospedeiro e formação de tecido ósseo novo, o que caracteriza uma incorporação de sucesso ${ }^{22}$.

Ainda em avaliação macroscópica, observou-se a não absorção do biopolímero, nem sua substituição por tecido ósseo novo. Ignácio ${ }^{11}$ e Maria ${ }^{12}$ obtiveram resultado semelhante ao estudarem a poliuretana de mamona em cães, não notando sua osteointegração. A avaliação histopatológica da implantação da poliuretana em ratos mostrou a presença de infiltrado inflamatório, predominantemente de neutrófilos e plasmócitos nos períodos iniciais e, posteriormente, de células mononucleares com acúmulo de tecido conjuntivo e sua substituição progressiva por tecido ósseo neoformado com a osteointegração do biopolímero ${ }^{24}$. Em cães, Ignácio ${ }^{11}$ observou a formação de tecido conjuntivo fibroso bem organizado e distribuído uniformemente em contato com toda a superfície da poliuretana de mamona. O tecido conjuntivo foi substituído gradativamente por tecido ósseo neoformado, com crescimento de tecido ósseo em toda superfície externa do biopolímero, mas sem sua osteointegração. Em estudo sobre os efeitos do polimetil metacrilato como cimento ósseo (cimento utilizado na técnica original) concluiu que ele aumenta a porcentagem de reabsorção do implante, com redução da formação óssea na região endosteal, porém com aumento da atividade osteoblástica na região periosteal. Houve a formação de tecido conjuntivo fibroso entre o cimento e o tecido ósseo neoformado ${ }^{25}$, como o observado com o uso da poliuretana de mamona. No presente trabalho, os exames histopatológicos confirmaram o encontrado por Ignácio ${ }^{11}$, observando-se a presença de tecido conjuntivo fibroso recobrindo o polímero do óleo de mamona sem que houvesse sua osteointegração com neoformação óssea em interfaces e externamente ao tecido conjuntivo. Foi notada a substituição gradual do tecido conjuntivo fibroso por tecido ósseo neoformado nos diferentes grupos, além da presença de neovasos, medula óssea ativa e infiltrado inflamatório mononuclear com 
redução gradual conforme o tempo de observação pósoperatória.

Baseando-se nos resultados obtidos, nota-se que a poliuretana de mamona mostrou comportamento similar ao observado com o uso do polimetil metacrilato na cirurgia de preservação do membro, sendo um bom substituto ao cimento original e o implante ósseo alógeno conservado em glicerina foi substituído por tecido ósseo neoformado apresentando funções osteoindutora e osteocondutora sem sinais de rejeição ou contaminação, com boa consolidação, mostrando que a glicerina é um bom meio conservador substituto à congelação. Portanto, a técnica preservadora do membro com suas modificações quanto ao meio de conservação do implante ósseo e ao cimento ósseo adotado caracterizouse como alternativa à técnica original e à amputação do membro para cães com osteossarcoma, merecendo ainda estudos quanto a seu uso em animais doentes.

\section{Conclusões}

1) A técnica de preservação do membro com suas modificações quanto ao meio de conservação do implante e cimento ósseo utilizado no canal medular dos implantes mostrou-se adequada e factível como substituta da técnica original.

2) A glicerina a $98 \%$ atuou como eficiente meio de conservação para os fragmentos ósseos, mantendoos livres de contaminação durante o período de estocagem, agindo como redutora da antigenicidade, preservando as funções de osteoindução e osteocondução, além de apresentar baixo custo.

3) A poliuretana de mamona mostrou ser um bom cimento ósseo, aumentando a resistência do implante ósseo, sendo biotolerante, atuando como bactericida, não havendo portanto a necessidade da adição de antibióticos ao polímero quando utilizado no canal medular dos implantes. Não foi observada a osteointegração da poliuretana de mamona.

\section{Referências}

1. Straw RC. Tumors of the skeleton system. In: Withrow SJ, MacEwen G (ed). Small animal clinical oncology. Philadelphia: WB Sauders; 1996. p. 287-315.

2. Ogilvie GK, Moore AS. Bone tumors. In: Ogilvie GK, Mooore AS. A practice manual - managing the veterinary cancer patients. New Jersey: Veterinary learning Stens; 1995. p 451-72.

3. LaRue SM, Withrow SJ, Power BE, Wrigley RH, Gillette EL, Schwarz PD, Straw RC, Richter SL. Limb-sparing treatment for osteosarcoma in dogs. J. Am. Vet. Med. Assoc. 1989; 195: 1734-44.

4. Costa JLO. Reconstrução de grande falha óssea com enxerto cortical alógeno conservado em glicerina, fixado com placa e parafusos de aço inoxidável da série 304. Estudo experimental em cães (Canis familiaris). [Dissertação - Mestrado]. Universidade Estadual Paulista - Faculdade de Ciências Agrárias e Veterinárias; 1996

5. Leite JBF, Marques AF, Gomes OM, Pigossi N. A glicerina e a preservação de tecidos. Revta. Paul. Med. 1979; 93: 81-4.

6. Costa Neto JM. Tenoplastia experimental do calcâneo comum em cães com peritônio bovino conservado em glicerina a $98 \%$. [Dissertação - Mestrado] Universidade Estadual Paulista Faculdade de Ciências Agrárias e Veterinárias; 1997.

7. O'Brien MG, Straw RC, Withrow SJ. Recent advances in the treatment of canine appendicular osteosarcoma. Small Animal Oncology: Continuing Education Article \# 3. 1993; 15: 939-46.

8. Straw RC, Withrow SJ. Treatment of canine osteosarcoma. In: Bonagura JD. Kirk's current veterinary therapy XII: small animal practice. Philadelphia: WB Saunders; 1995. p.506-11.

9. Ohara GH, Kojima KE, Rossi JC, Telles M, Soares JVC, Salomão C, Sanda M. Estudo experimental da biocompatibilidade do polímero da mamona implantada intra-óssea e intra-articular em coelhos. Acta Ortop. Bras 1995; 3: 62-8.

10. Ignácio $\mathrm{H}$, Mazzer $\mathrm{N}$, Barbieri $\mathrm{CH}$, Chierici G. Estudos sobre a aplicabilidade médica da poliuretana derivada da mamona. Res. Ortop. 1996; 6: 10-3.

11. Ignácio $\mathrm{H}$. Avaliação da poliuretana da mamona nas formas compacta e porosa no preenchimento de falha óssea: estudo experimental em cães. [Tese - Doutorado]. Universidade de São Paulo - Faculdade de Medicina; 1999.

12. Maria PP. Estudo da poliuretana de mamona (Ricinus communis) aplicada em defeito ósseo produzido experimentalmente na porção proximal medial da tíbia no cão, para estudo do desvio da crista tibial. [Dissertação - Mestrado]. Universidade Estadual Paulista - Faculdade de Ciências Agrárias e Veterinárias; 2001.

13. Straw RC, Withrow SJ. Limb-sparing surgery versus amputation for dogs with bone tumors. Vet. Clin. North Am.: Small Anim. Pract. 1996; 26: 135-43.

14. Pinto Jr HS. Utilização de enxertos ósseos homólogos preservados na reparação de fraturas cominutivas de ossos longos de cães. [Dissertação - Mestrado]. Universidade de São Paulo - Faculdade de Medicina Veterinária e Zootecnia; 1990.

15. Goodman LS, Gilman A. The pharmacological basis of therapeutics. 3.ed. Nova York: Mac Millian, 1965. p. 977.

16. Pigossi N, Raia A, Lex A, Gama AH, Simonsen O, Haddad J, Stolf NAG, Zerbini EJ, Miniti A, Tenuto R. Estudo experimental e clínico sobre o emprego, como implante, da dura-máter homógena conservada em glicerina à temperatura ambiente. Rev. Ass. Med. Brasil. 1971; 17 (8): 263-78.

17. Vasseur P. Limb preservation in dogs with primary bone tumors. Vet. Clin. North Am.: Small Anim. Pract. 1987; 17: 889-903.

18. Gebhardt MC, Flugtad DI, Springfield DS, Mankin HJ. The use of bone allografts for limb salvage in high-grade extremity osteosarcoma. Clin. Orthop. Rela. Res. 1991; 270: 181-96.

19. Straw RC, Withrow SJ, Powers BE. Management of canine appendicular osteosarcoma. Vet. Clin. North Am: Small Anim. Pract. 1990; 20: 1141-61.

20. Morello E, Buracco P, Martano M, Peirone B, Capurro C, Valazza A, Cotto D, Ferracini R, Sora M. Bone allografts and adjuvant cisplatin for the treatment of canine appendicular osteosarcoma in 18 dogs. J. Small Anim. Pract. 2001; 42 (2): 61-6.

21. Sinibaldi.K, Rosen H, Liu SK, DeAngelis M. Tumors associated with metallic implantes in animals. Clin. Orthop. Rel. Reas. 1976; 118: 257-66.

22. Burchardt H. Biology of bone transplantation. Orthop. Clin. North Am. 1987; 18 (2): 187-96. 
23. Rosso R, Schäfer D, Fricker R, Brennwals J, Jundt G, Spagnoli G, Harder F, Heberer M. Functional and morphological outcome of kee joint transplantation in dogs depends on control of rejection. Transplantation. 1997; 63 (12): 1723-33.

24. Carvalho TLL, Albuquerque Araújo CAC, Teófilo JM, Brentegani LG. Histologic and histometric evaluation of rat alveolar wound healing around polyurethane resin implants. Int. J. Oral Maxillofac. Surg. 1997; 26: 149-52

25. Straw RC, Power BE, Withrow SJ, Cooper MF, Turner AS. The effect of intramedullary polymethylmethacrylate on healing of intercalary cortical allografts in a canine model. J. Orthop. Res. 1992; 10 (3): 434-9.

\section{Agradecimentos}

Aos Profs. Drs. Júlio Carlos Canola e Antônio Carlos Alessi pelo auxílio na leitura dos exames radiográficos e histopatológicos e ao Prof. Gilberto Chierici por gentilmente ter cedido a poliuretana de mamona.

Ziliotto L, Fantinatti AP, Daleck CR, Padilha Filho JG, Souza AP, Diniz PPVP. A limb sparing surgery with the use of a cortical allograft preserved in glicerin: an experimental study in dogs. Acta Cir Bras [serial online] 2003 Mar-Apr;18(2). Available from URL: http://www.scielo.br/acb.

ABSTRACT - A limb-sparing surgery can be an alternative treatment to amputation for dogs with appendicular osteosarcoma. Purpose: The purpose of this study was the development of this surgical technique, similar to the original, described by Straw ${ }^{1}$, with changes in the procedure of the allografts preservation, and in the bone cement chose to be used intramedullary. Methods: The surgery was performed in six health dogs, with the osteotomy of one-third of the radio and ulna, section of the distal margin in the radio-carpal joint and reconstruction using a cortical allograft preserved in $98 \%$ glycerin. The allograft's medullar channel was filled with a polymer extracted from castor oil (Ricinus communis) and a long dynamic compression plate were used to fix this allograft on the radio, carpal joint and 3rd metacarpal bone, with the arthrodesis of the carpal joint. A medio-lateral radiographs was performed immediately posteoperatively and with $7,15,30,45$, $60,90,120$ and 150 days after surgery, to evaluate the allograft incorporation. The histopatological evaluation was done with 90, 120 and 150 days after surgery. Results: Was notice a bone callus formation on the radiogrhphs exams by 60 days after surgery and bone bridges were closing the interfragmentary space, with remodeling by 90 days. We have noticed resorption of the grapht, with formation of a connective tissue and new bone around the polymer on the histophatological evaluation. A neovascularization and inflammatory cells in the connective tissue was noticed with a decreased in the inflammatory process with the time. Conclusions: The polymer extracted from castor oil showed to be a good substitute for the bone cement originally used in the limb-sparing surgery, increasing the graft resistance with no foreign body reaction or osteointegration. The allograft preserved in glycerin presented onteoinduction and osteocondution actions, with new bone formation, and no signs of rejection, then, the glycerin showed to be a good alternative preservation procedure. Therefore, the modified technique can be considered an alternative to the original limb-sparing surgery and to amputation for dogs with appendicular osteosarcoma, studies still deserve to be done with sick animals.

KEY WORDS - Osteosarcoma. Glycerin. Polymer extracted from castor oil. Limb-sparing. Cortical allograft.

Conflito de interesse: nenhum Fonte de financiamento: FAPESP

Correspondência:

Liane Ziliotto

Rua João Nogueira de Carvalho, 250

14096-150 Ribeirão Preto - SP

Tel: (16)624-9442

lianeziliotto@yahoo.com.br

Data do recebimento: $15 / 01 / 2003$

Data da revisão: 28/01/2003

Data da aprovação: 03/02/2003 